\title{
Development and Validation of the Spiritual Impact Rating Scale for Women (SIRSW): A Tool for Assessing College Women's Spirituality
}

\author{
Angela U. Ekwonye ${ }^{1}$, Verna DeLauer ${ }^{2} \&$ Terrence F. Cahill ${ }^{3}$ \\ ${ }^{1}$ Department of Public Health, St. Catherine University, St. Paul, Minnesota, USA \\ ${ }^{2}$ Department of Environmental Studies, Franklin Pierce University, Rindge, New Hampshire, USA \\ ${ }^{3}$ Department of Interprofessional Health Sciences and Health Administration, Seton Hall University, South \\ Orange, New Jersey, USA
}

Correspondence: Angela U Ekwonye, Department of Public Health, St. Catherine University, 2004 Randolph Ave, St. Paul, MN, USA. Tel: 651-690-6928. E-mail: amekwonye034@stkate.edu

Received: May 10, 2019 Accepted: June 12, 2019 Online Published: June 17, 2019

doi:10.5539/gjhs.v11n7p128 URL: https://doi.org/10.5539/gjhs.v11n7p128

\begin{abstract}
Spirituality impacts college student outcomes in the United States such as mental health, physical health, academic success, and healthy behaviors. Numerous studies consistently show gender differences on spirituality measures. The wealth of empirical evidence demonstrating gender differences in spirituality warranted the development of a tool for measuring college women's spirituality. The purpose of this study was to develop and examine the psychometric properties of the SIRSW, including its content validity, factorial structure, and internal consistency using a college women sample. A sample of 667 undergraduates (ages 18-26) at an all-women's Catholic University in the upper Midwest completed the spirituality survey in Spring 2018. Demographic characteristics were analyzed using descriptive statistics. Demographic differences in spirituality score were assessed using t-test and one-way ANOVA. Psychometric characteristics of the SIRSW were assessed by evaluating variability, internal consistency reliability, and overall scale structure. There were no significant demographic differences in total spirituality score. Internal consistency was high $($ Cronbach alpha $=0.97)$. Item-scale coefficients were above the minimum criteria. Factor analysis revealed that the 16-items measuring spirituality fell under the one-factor component and accounted for $82 \%$ of the variance. The SIRSW was found to be a valid and reliable tool for assessing the spiritual well-being of college women. Understanding college women's spirituality can inform the development of a spiritually oriented intervention that is consistent with their values enhancing their psychological, mental, and physical well-being.
\end{abstract}

Keywords: spiritual, impact, validation, rating scale, women

\section{Introduction}

\subsection{Background}

Spirituality is the process of striving for greater connectedness to self, others, and/or a higher power or nature; from which one derives a sense of meaning in life; and transcendence beyond self, everyday living, and suffering (Weathers, McCarthy, \& Coffey, 2016). Spirituality provides one with personal meaning, social and inner resources they can call on in adverse situations (Pargament, 2001). Spirituality may help sustain valued health behavior and influence one's self-esteem and sense of belonging (Musgrave, C. E. Allen, \& G. J. Allen, 2002). Research shows that students come to college in the U.S. not only with a desire to study and explore potential job and career opportunities but to find a sense of direction by addressing questions of meaning and purpose in life (Shin \& Steger, 2016). Increasing numbers of college students not only consider themselves spiritual but seek out opportunities to help them grow spiritually (Kuh \& Gonyea, 2006; Astin et al., 2004). Spirituality impacts student outcomes such as mental health (Dhama et al., 2017; Deb, McGirr, \& Sun, 2016), academic resilience, (Ekwonye \& DeLauer, 2019), and healthy behaviors (Hooker, Masters, \& Carey, 2014; Mehri, Solhi, Garmaroudi, Nadrian, \& Sighaldeh, 2016). A review of 20 research studies found a positive association between relational spirituality and quality of life across different age groups, including young adults (Counted, Possamai, \& Meade, 2018). Spirituality can hold different meanings to different individuals. For some, spirituality is a part of organized religion such as going to church, temple, or mosque (Hooker, Masters, \& Carey 2014). Others consider it very 
personal (Reed, 1987), and some become attached to their spiritual side through prayer, meditation, silence, yoga, nature walk, etc. (Puchalski \& Romer 2000). Gender-identity appears to influence the way that an individual perceives and expresses spirituality (Agha, Maqbool, \& Javed, 2016).

\subsection{Gender-Based Differences in Spirituality}

The notion of gender differences has been reported on different aspects of human development implicitly or explicitly, whether it be in terms of women's distinctive forms of moral reasoning (Gatens-Robinson, 1986; Ryan, David, \& Reynolds, 2004; Ward \& King, 2018), ways of knowing (Belenky et al., 1986), emotionality (Miller, 1976), styles of relational attachment or identity formation (Josselson, 1987), and religiosity (Bryant, 2007; Johnson \& Reynolds, 2018). Differences in all of these facets of human development lead to the beliefs that gender differences in spirituality may exist as well. It has been suggested that college women experience to a greater extent a strong relational spirituality in terms of daily connection with God through prayer, seek spiritual direction when handling personal problems, and feel assured that God is present and active in their lives. College women tend to derive comfort and security from faith and express feelings of devotion to and reverence for God compared to their male counterparts (Buchko, 2004). While some studies found that men benefit from public religious activity in comparison to women within some religious denominations, having spiritual experiences is important to women (Hammermeister et al., 2005). Over the past 20 years, there have been a number of spirituality assessment studies where female students scored higher than males in spiritual well-being (Bryant, 2007; Jafari et al., 2010). Gender differences in spirituality were found in a study of 60 college students. Using the Expressions of Spirituality Inventory, the authors found that males scored higher in the cognitive domain, whereas females scored higher in the experiential domain (Agha, Maqbool, \& Javed, 2016). The authors argued that men and women do not differ in their levels of spirituality, but in the ways they conceive and express it.

Gender differences in spirituality have been linked to the concept of connected and separate ways of knowing (Belenky et al., 1986; Aldegether, 2017). According to the authors, connected knowers focus on relationships, feelings, and understanding others, while separated knowers favor moral objectivity restricting their personal feelings. Belenky et al. (1986) claimed that women are more likely to use connected knowing, while men are more likely to use separate knowing. Scholars of women spirituality have often depicted the connections between women's spirituality and their relationships with others (Ochs, 1983; Shukla et al., 2016). The notion of "being in relationship" as fundamental to women's spirituality was recognized by Bergin (1988) who also acknowledged that men form relationships with others. However, the difference lies in their style of being in a relationship (Al-Natour, 2017). While women focus on the personal connections formed with a loving God and with members of their religious communities, men feel drawn to God's power and judgment and on practicing spiritual discipline (Ozorak, 1996; Nadeem, 2015). Since evidence indicates that women's spirituality centers on "being in relationships" compared to men, one can argue that an exclusive instrument is required to gauge women's spirituality effectively. The Spiritual Impact Rating Scale for Women (SIRSW) satisfies that need as it was designed to measure perceived relational nature of women's spirituality, i.e., the extent to which women derive inner strength, support, meaning, and purpose in life through their relationships with self, others, and a Higher Power.

\subsection{Existing Measures of Spirituality}

Several instruments that measure spirituality have been used in both male and female populations without considering that males and females express and conceive their spirituality differently. One instrument is the Spiritual Well-Being Scale (SWBS) which is the most commonly used measure of spirituality (Paloutzian \& Ellison 1982) and is based on monotheistic traditions such as tenets of Judeo-Christian religion, which excludes individuals from other spiritual traditions. For instance, an item from the SWBS: "I believe that God is concerned about my problems," implies membership in a Judeo-Christian belief system. The new measure (SIRSW) addresses this limitation by measuring spirituality as an experience of connection with a Higher Power, and as such could appeal to women from different spiritual backgrounds regardless of religious affiliation. Bufford, Paloutzian, and Ellison (1991) noted that the SWBS has ceiling effects that skew data, particularly in religious populations, while Genia (2001) calls into question its validity among groups other than those from the Judeo-Christian background. Beside the SWBS, other spirituality instruments such as the Spiritual Assessment Inventory (SAI) (Hall \& Edwards 1996), Index of Core Spiritual Experiences (INSPIRIT) (Kass et al., 1991) are also based only on the Judeo-Christian religion. While other spirituality instruments appear to measure spirituality in young adults including college students, they did not recognize the existence of gender differences in spirituality (Hodge, 2003; Jagers \& Smith, 1996; MacMillan \& Luna, 2016). In light of increasing evidence in recent times supporting gender differences in spiritual well-being and women's tendency towards a relational form of spirituality (Desrosiers \& 
Miller, 2007; Bryant, 2007; Buchko, 2004; Hammermeister et al., 2005; Jafari et al., 2010), no tool has been exclusively developed to truly assess college women's relational spirituality.

\subsection{Is a Separate Tool Needed to Assess Women's Spirituality?}

The question of whether or not separate tools are needed to measure spirituality in males and females is currently unresolved. In some samples, there was no relationship between spirituality scores and gender (Agha, Maqbool, \& Javed, 2016; Bufford, 1984). In other instances, gender differences were observed (e.g., Hammermeister et al., 2005; Jafari et al., 2010). On whether items on the most popular tool - the SWBS show differential item functioning (DIF) between gender groups, Kellums (1995) found that mean scores for the older adult population in graduate school were almost identical for males and females thus showing no gender differences for total SWBS score. However, in the younger adult population, females' mean scores were almost five points higher than the males on the SWBS. Although Bufford, Paloutzian, and Ellison (1991) acknowledged the existence of gender differences in spirituality but argued that it was not necessary to provide separate norms for males and females due to limited empirical information comparing men and women's spirituality in the ' 80 s and 90 's. More recently, an increasing number of research studies are strongly and consistently showing that gender differences in spirituality exist with women tending to a relational spirituality (Desrosiers \& Miller, 2007; Sandage, 2017), thus necessitating the need to develop a separate tool to measure spirituality in college women. The new measure called the 'Spiritual Impact Rating Scale for Women' (SIRSW) was designed to assess college women's spirituality. The purpose of this study was to develop and examine the psychometric properties of the Spiritual Impact Rating Scale for Women (SIRSW) including its content validity, factorial structure, and internal consistency using a college women sample.

\section{Methods}

\subsection{Development of the Spiritual Impact Rating Scale for Women (SIRSW)}

The creation of the SIRSW and content validation was carried out in phases. The purpose of the first phase was to generate a pool of items for the questionnaire. Items were created after an extensive review of the literature and a cursory inspection of existing spirituality instruments including the comprehensive list of measures of religiosity (Hill \& Hood, 1999). While the existing instruments contain some useful and meaningful items, no single tool appeared to be completely suited for measuring the relational nature of women' spirituality. This initial review led to the creation of a total of 22 items relevant to college women's spirituality.

\subsection{Content Validation}

In the second phase, the 22 items were reviewed for content validity by the University Chaplain, one Catholic nun, three graduate and two undergraduate students, a panel from the University's Office of Institutional Research, Student Support and Retention, and Academic Advising. Items were evaluated individually for simplicity, clarity, and relevance for women population. Ambiguous terms were either removed or reworded. For instance, one item was rephrased, and three items that were considered irrelevant for use in the female population were removed. In the end, 19 items were deemed valid for measuring the influence of spirituality in college women population.

\subsection{Sample and Setting}

The study was conducted at an all-women's college in the upper Midwest. The University has three colleges: Graduate College, College for Women, and College for Adults. The Graduate College and the College for Adults are coeducational. The 19 Spiritual Impact Rating Scale for Women (SIRSW) items were added to the institutional Mapworks survey. Students in the College for Women are highly encouraged by the institution to fill out the Mapworks online survey administered twice a year. The Mapworks online survey is designed to gather information about college students experience so that necessary support services can be provided primarily to at-risk students. The Mapworks survey contained institution-specific questions and SIRSW items. All 2,361 students enrolled in the college for women were eligible to participate in the study. A total of 672 students completed the survey yielding a response rate of $28.46 \%$. This sample size was adequate for exploratory factor analysis (Comrey \& Lee, 2013). This setting was selected due to the presumption that women attending the University have knowledge of spirituality and are aware that they are a part of a spiritual community.

\subsection{Inclusion/Exclusion}

To be eligible to participate in the study, the student must be currently enrolled in the College for Women in Spring 2018. Students were excluded if they were not actively enrolled in that semester.

\subsection{Procedure}

After the Institutional Review Board (IRB) approval, a total of 2,361 students in the College for Women were invited to complete the University Mapworks online survey through the Office for Student Support and Outreach. 
Participants completed the consent form which contained information about the purpose of the study, risks and benefits, and the rights to withdraw from the study at any time without penalty. Data collection occurred for two weeks. Academic Advisors were emailed and asked to promote survey participation among their students verbally or through their emails. About 3-4 email reminders were automatically generated and sent to students through the Mapworks web server. To increase the response rate, participants were offered incentives for participation (e.g. reserved parking spot on the campus for spring term, creative cooking class, framed diploma for graduating seniors, early room residence hall sign up, dessert or hot beverage tickets, and $\$ 50$ gas card). Completion of the survey took approximately 15 minutes. Survey data downloaded from Mapworks were stored on secured drives on password-protected computers. To ensure confidentiality, student data were aggregated and de-identified before analysis.

\subsection{Data Collection}

The SIRSW contains 19 items intended to reflect on the notion of "being in relationship." Some examples of items include 1) "To what degree does your spirituality define your relationships?" 2) "To what extent do you feel a sense of connection with Higher Power that transcends your personal self?" 3) "To what degree do your spiritual beliefs provide you with support and guidance?" 4) "To what degree does your spirituality give meaning and purpose to your life?" These items are intended to reflect a sense of relatedness to oneself, to others, to nature or the world, and to a Higher Power. Items are rated and scored on a 7-point scale. Responses range from 1 (Not at all), 4 (Moderately) to 7 (Extremely). The advantage of using a 7-point rating scale instead of a 5-point is the higher potential for differentiation in judgments made (Krosnick, 2018). Also, having verbal labels (not at all, moderately, extremely) may be beneficial, because they may clarify the meanings of the scale points and at the same time reduce respondent burden by removing a step from the cognitive processes involved in answering the question (Krosnick, 2018). The scores are summed up to provide total scores ranging from 16 to 112, with higher scores indicating higher spirituality.

\subsection{Statistical Analysis}

Data were analyzed using the Statistical Package for the Social Sciences (SPSS) version 24.0. Before analysis, data were checked for missing values and outliers. Descriptive statistics were used to analyze the demographic characteristics of the sample. Demographic differences in spirituality were tested using t-test and a one-way ANOVA. Psychometric characteristics of the SIRSW were assessed by evaluating variability, internal consistency reliability, and overall scale structure. Normality of the distribution was assessed by observing the range of scores, evaluating the frequency distributions and symmetry. Scores that are distributed across the full range of values indicate that a tool has good variability within the specified group of individuals. In a normally distributed sample, the mean, median, and mode should be similar. Symmetry was assessed by calculating the skewness and kurtosis statistics. Skewness evaluates the extent to which a distribution of values deviates from symmetry around the mean. Kurtosis examines the extent to which distribution is peaked or flat relative to a normal distribution and is another indicator of variability. Skewness and kurtosis values of $+/-1$ to $+/-2$ are acceptable for psychometric purposes and represent a more normal distribution. Internal consistency reliability estimates the extent to which individual items within a scale are correlated with the other scale items in a given sample. Reliability of the SIRSW was interpreted by calculating a Cronbach alpha coefficient. A Cronbach's alpha of 0.70 and above are considered an acceptable criterion of internal reliability. A high value of alpha is evidence that the items measure the underlying construct (Portney \& Watkins, 2009). Item-scale correlations assess the homogeneity of the tool and how well the items represent the construct of interest. A corrected item-scale correlation greater than .30 is commonly used (Portney \&Watkins, 2009).

The SIRSW was evaluated for its factor structure with exploratory factor analysis (principal component analysis). Before performing the principal component analysis, the adequacy of data for factor analysis was assessed using Kaiser-Meyer-Olkin (KMO) test, a test for sampling adequacy and Bartlett's Test of Sphericity, a test of the suitability of the correlation matrix for factor analysis (Stevens, 2012). For factor analysis, the cut-off for item values of communality was 0.50 . The criterion for factor extraction was an eigenvalue $>1$ and factor loading of $>$ 0.70 . The number of factors extracted was confirmed by visually examining the scree plot (Yong \& Pearce, 2013).

\section{Results}

\subsection{Demographics}

The SIRSW was tested in an all-female sample. A total of 672 college women completed the survey. Five students were dropped from the analysis because they completed only one survey item giving a final sample size of 667 . Demographic characteristics of participants are displayed in Table 1. One-way analysis of variance did not reveal 
significant differences in total spirituality score among the four educational levels, age groups, ethnic groups, religious affiliation, and type of major. T-test analysis did not show significant differences in total spirituality score between on-campus and off-campus students.

Table 1. Demographic characteristics of participants

\begin{tabular}{|c|c|c|c|c|}
\hline Characteristics & Frequency (\%) & Mean & SD & p-value \\
\hline Class Rank & & & & 0.27 \\
\hline 1st Year/Freshman & $88(13.2)$ & 59.42 & 32.61 & \\
\hline Sophomore & $201(30.1)$ & 64.57 & 30.43 & \\
\hline Junior & $180(27.0)$ & 63.49 & 31.82 & \\
\hline Senior & $198(29.7)$ & 66.32 & 28.57 & \\
\hline Age & & & & 0.81 \\
\hline 18-19 years & $116(17.4)$ & 62.20 & 29.87 & \\
\hline 20-21 years & $308(46.2)$ & 63.72 & 31.55 & \\
\hline $22-23$ years & $182(27.3)$ & 65.00 & 30.16 & \\
\hline $24-25$ years & $29(4.3)$ & 66.66 & 27.62 & \\
\hline $26+$ years & $32(4.8)$ & 67.59 & 29.78 & \\
\hline Race & & & & 0.45 \\
\hline White & $420(63.0)$ & 62.96 & 30.33 & \\
\hline Black or African American & $49(7.3)$ & 69.02 & 28.55 & \\
\hline Asian & $83(12.4)$ & 65.04 & 30.44 & \\
\hline Hispanic or Latino & $57(8.5)$ & 68.16 & 30.47 & \\
\hline Two or more races & $32(4.8)$ & 60.66 & 34.63 & \\
\hline Nonresident Alien & $8(1.2)$ & 81.25 & 22.95 & \\
\hline American Indian/Alaska Native & $2(.3)$ & 57.00 & 57.98 & \\
\hline Unknown & $16(2.4)$ & 59.63 & 36.53 & \\
\hline${ }^{\mathrm{a}}$ Religion & & & & 0.28 \\
\hline Catholic & $110(16.5)$ & 61.44 & 30.63 & \\
\hline Protestant & $149(22.3)$ & 61.44 & 30.72 & \\
\hline Muslims & $14(2.1)$ & 55.21 & 32.43 & \\
\hline Hindu & $3(.4)$ & 46.00 & 37.47 & \\
\hline Buddhist & $10(1.5)$ & 64.00 & 32.75 & \\
\hline Agnostic & $29(4.3)$ & 57.72 & 34.74 & \\
\hline Jewish & $3(.4)$ & 90.67 & 12.89 & \\
\hline No religious affiliation & $119(26)$ & 66.82 & 30.90 & \\
\hline${ }^{\mathrm{a}}$ Major & & & & 0.06 \\
\hline SHAS & $225(33.7)$ & 60.99 & 30.72 & \\
\hline HSSH & $311(46.6)$ & 64.44 & 29.70 & \\
\hline SBPS & $112(16.8)$ & 69.46 & 31.21 & \\
\hline Type of Residence & & & & 0.60 \\
\hline Off-campus & $347(52.0)$ & 64.59 & 30.43 & \\
\hline On campus & $320(48.0)$ & 63.61 & 30.78 & \\
\hline
\end{tabular}

${ }^{\mathrm{a}}$ Missing data: participants left the item blank.

SHAS (School of Humanities, Arts, and Sciences), HSSH (Henrietta Schmoll School of Health), SBPS (School of Business and Professional Studies). 


\subsection{Variability}

Cases that had a missing value in at least one of the items were dropped. The analysis was run on cases which had a complete set of data $(n=554)$. Psychometric properties of the SIRSW are shown in Table 2. The mean and standard deviation of the SIRSW total score (sum of the 16 items) of the whole sample was 64.12 (30.58). Participants used the full range of possible responses providing reasonable evidence of variability. The distribution is approximately symmetric with a slight negative skew, indicating that participants responded more toward the higher end of the scale.

Table 2. Spiritual Impact Rating Scale for Women (SIRSW) Descriptive Statistics and Reliability

\begin{tabular}{ll}
\hline Scale Statistics & \\
\hline Number of items & 16 \\
Missing items & $0 \%$ \\
Mean (SD) & $64.12(30.58)$ \\
Median & 66.00 \\
Skewness & -0.19 \\
Kurtosis & -1.19 \\
Possible range & $1-7$ \\
Observed range & $1-7$ \\
Internal consistency reliability & 0.97 \\
Range of corrected item-total correlations & $0.82-0.93$ \\
\hline
\end{tabular}

The mean scores of the individual items ranged from 3.49 to 4.54 (Table 3). The item "I feel connected to others in my spiritual community" was the item with the lowest mean score, while "My spiritual beliefs are one of the most important things in my life" was the item with the highest mean score.

Table 3. Spiritual Impact Rating Scale for Women (SIRSW) Item Means and Standard Deviations

\begin{tabular}{lll}
\hline SIRSW Item Means and Standard Deviations & Mean & SD \\
\hline Q1. My spiritual beliefs are one of the most important things in my life & 4.54 & 2.14 \\
Q2. Integrating spirituality into my life is personally important to me & 4.25 & 2.17 \\
Q3. I seek out opportunities to grow spiritually & 4.03 & 2.07 \\
Q4. My spirituality gives meaning and purpose to my life & 4.37 & 2.15 \\
Q5. My spiritual beliefs help me to find meaning in times of hardship & 4.44 & 2.24 \\
Q6. My spirituality helps define the goals I set for myself & 3.95 & 2.15 \\
Q7. My spirituality has helped me develop my identity & 4.15 & 2.14 \\
Q8. My spiritual beliefs define my relationships & 3.70 & 2.06 \\
Q9. My spirituality informs my ethical behavior & 4.42 & 2.16 \\
Q10. My spiritual beliefs provide me with support and guidance & 4.25 & 2.16 \\
Q11. My spirituality lies behind my whole approach to life & 4.14 & 2.12 \\
Q12. I have an interest in spirituality & 3.93 & 2.04 \\
Q13. I feel a sense of connection with Higher Power that transcends my personal self & 3.92 & 2.21 \\
Q14. I feel connected to others in my spiritual community & 3.49 & 2.04 \\
Q15. I experience spiritual strength by trusting in a Higher Power & 3.98 & 2.20 \\
Q16. I experience deep inner peace through meditation, prayer, or some other spiritual practices & 3.91 & 2.10 \\
\end{tabular}


Responses: Not at all 1 2

$$
\text { Moderately }
$$

3
45
Extremely

\section{$6 \quad 7$}

\subsection{Factor Structure}

The number of valid cases (those free of missing data) for exploratory factor analysis was 554. The Kaiser-Meyer-Olkin (KMO) test and Bartlett's Test of Sphericity were used to examine the appropriateness of Factor Analysis. The KMO statistic of 0.976 was large (higher than 0.50). Bartlett's Test of Sphericity was significant with a p-value of $<0.0001\left(\chi^{2}=13798.6, d f=136\right)$ Therefore, factor analysis is considered an appropriate technique for further analysis of the data. An exploratory principal component analysis was performed to examine the dimensionality of the SIRSW. Only one component was extracted, so the solution was not rotated. Nearly all items loaded highly on the first factor with an eigenvalue of 14.38 , explaining $75.7 \%$ of the variance. Item loadings ranged from 0.62- 0.89. Three items: 1) "My spirituality helps me to attain inner peace," "I feel good about the direction in which my life is headed," and "It is important that this institution encourages personal expression of spirituality" had loadings of $0.63,0.62$, and 0.69 respectively. These items did not also achieve the cut-off of 0.50 for item values of communality and were dropped from the analysis (table not shown). A second-factor analysis was conducted for the final 16-item one-factor solution, and loadings ranged from 0.84 to 0.94 (Table 4). An eigenvalue of 13.1 was obtained accounting for $82.0 \%$ of the variance. An examination of the scree plot supported the unidimensionality of the SIRSW.

Table 4. Principal components analysis factor loadings for the SIRSW items

\begin{tabular}{lll}
\hline Item & Factor 1 & Communalities \\
\hline Q1. My spiritual beliefs are one of the most important things in my life & 0.91 & 0.84 \\
Q2. Integrating spirituality into my life is personally important to me & 0.91 & 0.84 \\
Q3. I seek out opportunities to grow spiritually & 0.87 & 0.77 \\
Q4. My spirituality gives meaning and purpose to my life & 0.94 & 0.89 \\
Q5. My spiritual beliefs help me to find meaning in times of hardship & 0.93 & 0.87 \\
Q6. My spirituality helps define the goals I set for myself & 0.92 & 0.86 \\
Q7. My spirituality has helped me develop my identity & 0.92 & 0.85 \\
Q8. My spiritual beliefs define my relationships & 0.89 & 0.79 \\
Q9. My spirituality informs my ethical behavior & 0.87 & 0.76 \\
Q10. My spiritual beliefs provide me with support and guidance & 0.94 & 0.88 \\
Q11. My spirituality lies behind my whole approach to life & 0.93 & 0.86 \\
Q12. I have an interest in spirituality & 0.89 & 0.79 \\
Q13. I feel a sense of connection with Higher Power that transcends my personal self & 0.92 & 0.84 \\
Q14. I feel connected to others in my spiritual community & 0.84 & 0.72 \\
Q15. I experience spiritual strength by trusting in a Higher Power & 0.90 & 0.82 \\
Q16. I experience deep inner peace through meditation, prayer, or some other & 0.84 & 0.71 \\
spiritual practices & &
\end{tabular}

$\mathrm{N}=554 ;$ Note. Only one component was extracted. The solution was not rotated.

\subsection{Scale Reliability}

The internal consistency reliability estimates with Cronbach's alpha was very high, 0.97 for the 16 -item scale. The inter-item correlation was used to determine how well individual items fit in the overall scale. All item-pairs had correlations above 0.60 . All corrected item-total correlations were positive, with corrected item-total correlations between 0.82 and 0.93 (Table 2). 


\section{Discussion}

The present study did not find significant differences in total spirituality scores among educational levels, age groups, ethnic groups, religious/spiritual background, type of major, and residence. Additionally, these demographic variables did not significantly predict SIRSW scores. On whether to develop separate norms for measuring spirituality in men and women, Bufford, Paloutzian, and Ellison (1991) doubted the need due to limited studies in this area at the time. In recent years, numerous studies are consistently showing that men and women score differently on spirituality measures, with college women not only having higher scores in spirituality (Buchko, 2004; Hammermeister et al., 2005; Jafari et al. 2010), but indicated interest in integrating spirituality into their lives and seeking spiritual virtues in life (Bryant, 2007) consistent with the findings of the present study. The wealth of empirical evidence demonstrating that men and women are simply different in the way they experience and express their spirituality warranted the development of the new measure, the Spiritual Impact Rating Scale for Women (SIRSW). The SIRSW was designed to capture the perceived relational nature of college women's spirituality by using a case study in which women are implicitly or explicitly connected to spirituality. This study explores the psychometric properties of SIRSW in a sample of female college students. Study results provide evidence of the reliability and validity of the SIRSW items in measuring spirituality college women population. Internal consistency was high in this sample of female college students; it could not be compared with findings from other studies since there are no current instruments that exclusively tap college women's spirituality. Item-scale coefficients were above the minimum criteria, demonstrating the homogeneity of the scale items in measuring the construct of spirituality. Overall, the results suggest that the SIRSW exhibits good evidence of internal consistency reliability. Factor analysis revealed that the 16-items measuring spirituality fell under the one-factor component and accounted for $82 \%$ of the variance. The items on the scale reflect relational connectedness which is central to college women's spirituality (Bryant, 2007; Buchko, 2004). Thus, items in the SIRSW captures college women's relational spirituality as the extent to which they derive inner strength, support, meaning, and purpose in life through their relationships with self, others, and their Higher Power.

The role spirituality plays in helping women find solace and comfort, meaning and purpose in their lives, positive birth, and mothering experiences, and dealing with personal and work-related challenges has been fairly well established (Blakey, 2016; Moloney \& Gair, 2015; Reid, Roumpi, \& O'Leary-Kelly, 2015; Dailey \& Stewart, 2007). Since college women are increasingly committed to integrating spirituality into their lives, healthcare practitioners on or off campus may wish to use the SIRSW to conduct a spiritual assessment of their young female client. Results of such evaluation may provide insight as to the inner resources available to the young college woman. Such internal assets can be drawn upon to help them deal with stressful life events. The tool may also be used to understand the importance of spirituality in the lives of young women since young women who are highly committed to their spiritual beliefs and practices may be open to receiving a spiritually oriented intervention that is consistent with their values. This study was conducted in an all-female college sample and may inform our understanding of the spirituality of college-aged women and how healthcare professionals on college campuses can better work with them to support their spiritual growth. The study obtained a moderate to high spirituality scores and thus may suggest to college administrators the need to endorse the role of spirituality in the lives of their female college students. To further support the spiritual well-being of women on college campuses, college administrators may create space and opportunities that promote spiritual practices on college campuses. Since college women's spirituality is centered on being in a relationship, college administrators can encourage and promote the development and implementation of a spiritual mentorship program or community support network as suggested by Parks (2011) for students to feel safe in exploring the questions of meaning and purpose in life. College administrators can also track the level of spirituality of their female students using the SIRSW and monitor how it relates to retention, commitment, and completion.

This study has some limitations which provide opportunities for future research. First, utilizing a convenience sample limits the generalizability of the findings. Second, the use of cross-sectional design did not permit the assessment of the temporal relation of the variables. Third, participants may have given socially desirable responses that may not be reflective of their true feelings. Fourth, is the use of female college sample, whose characteristics may not reflect typical women community samples, but understanding that population in and of itself is crucial. Further research could validate the scale in a diverse college women sample.

\section{Conclusion}

This study assessed the relational nature of college women's spirituality using a newly developed tool, the SIRWS. The SIRSW was validated using a sample of female college students. The focus of this scale on relational spirituality allows this scale to be used with college women from a wide range of backgrounds similar to the 
sample study. Further research could investigate the validity and usefulness of the scale among women in other college campuses. Future research could also test the scale with a wide range of student outcomes including lifestyle factors, academic behaviors and ethics, retention, and completion. The present study supports the concept of connected knowing which is fundamental to women's spirituality. Overall, the SIRSW scale was found to be a valid and reliable instrument for assessing perceived relational spirituality in college women.

\section{Acknowledgements}

We would like to thank Dr. Alvina Brueggemann, Ellen Richter-Norgel, Lindsay Whipple, Dr. Brian Dusbiber, and Rev. Cyprian Onyeihe for their guidance, assistance with data collection, and support of this research.

\section{Competing Interests Statement}

There was no potential conflict of interest.

\section{References}

Agha, F., Maqbool, S., \& Javed, S. (2016). Gender differences in spirituality among college students. Indian Journal of Positive Psychology, 7(4), 450.

Aldegether, R. (2017). Women's ways of knowing among female Saudi student teachers: Implications for teaching and learning [online]. Issues in Educational Research, 27 (1), 1-18.

Al-Natour, A., Al Momani, S. M., \& Qandil, A. M. A. (2017). The Relationship Between Spirituality and Quality of Life of Jordanian Women Diagnosed with Breast Cancer. Journal of Religion and Health 56, 2096.

Astin, A. W., Astin, H. S., Lindholm, J. A., Bryant, A. N., Szelényi, K., \& Calderone, S. (2005). The spiritual life of college students: A national study of college students' search for meaning and purpose. Los Angeles, CA: UCLA Higher Education Research Institute.

Blakey, J. M. (2016). The role of spirituality in helping African American women with histories of trauma and substance abuse heal and recover. Social Work and Christianity, 43(1), 40.

Belenky, M. F., Clinchy, B. M., Goldberger, N. R., \& Tarule, J. M. (1986). Women's ways of knowing: The development of self, voice, and mind (Vol. 15). New York: Basic books.

Bergin, A. E. (1988). Women's Psyche, Women's Spirit: The Reality of Relationships. Psyccritiques, 33(2), 169-170. https://doi.org/10.1037/025438

Buchko, K. J. (2004). Religious beliefs and practices of college women as compared to college men. Journal of College Student Development, 45(1), 89-98. https://doi.org/10.1353/csd.2004.0004

Bryant, A. N. (2007). Gender differences in spiritual development during the college years. Sex roles, 56(11-12), 835-846. https://doi.org/10.1007/s11199-007-9240-2

Bufford, R. K., Paloutzian, R. F., \& Ellison, C. W. (1991). Norms for the Spiritual Well-Being Scale. Journal of psychology and theology, 19(1), 56-70. https://doi.org/10.1177/009164719101900106

Comrey, A. L., \& Lee, H. B. (2013). A first course in factor analysis. Psychology press. https://oi.org/10.4324/9781315827506

Counted, V., Possamai, A., \& Meade, T. (2018). Relational spirituality and quality of life 2007 to 2017: an integrative research review. Health and quality of life outcomes, 16(1), 75. https://doi.org/10.1186/s12955-018-0895-x

Dailey, D. E., \& Stewart, A. L. (2007). Psychometric characteristics of the spiritual perspective scale in pregnant African-American women. Research in Nursing \& Health, 30(1), 61-71. https://doi.org/10.1002/nur.20173

Deb, S., McGirr, K., \& Sun, J. (2016). Spirituality in Indian University students and its associations with socioeconomic status, religious background, social support, and mental health. Journal of religion and health, 55(5), 1623-1641.

Desrosiers, A., \& Miller, L. (2007). Relational spirituality and depression in adolescent girls. Journal of clinical psychology, 63(10), 1021-1037. https://doi.org/10.1002/jclp.20409

Dhama, K., Gupta, R., Singla, A., Patthi, B., Ali, I., Niraj, L. K., ... \& Prasad, M. (2017). An Insight into Spiritual Health and Coping Tactics among Dental Students; A Gain or Blight: A Cross-sectional Study. Journal of clinical and diagnostic research: $J C D R, 11(8), \mathrm{ZC} 33$.

Ekwonye, A. U., \& DeLauer, V. (2019). Exploring individual and interpersonal level factors associated with academic success of college students at a women's, faith-based higher institution. Higher Education Studies, 
9(1), 86- 99. https://doi.org/10.5539/hes.v9n1p86

Gatens-Robinson, E. (1986). In a Different Voice: Psychological Theory and Women's Development. In The Personalist Forum (Vol. 2, No. 2, pp. 150-152). University of Illinois Press.

Genia, V. (2001). Evaluation of the spiritual well-being scale in a sample of college students. The International Journal for the Psychology of Religion, 11(1), 25-33. https://doi.org/10.1207/S15327582IJPR1101_03

Hall, T. W., \& Edwards, K. J. (1996). The initial development and factor analysis of the Spiritual Assessment Inventory. Journal of Psychology and Theology, 24(3), 233-246. https://doi.org/10.1177/009164719602400305

Hammermeister, J., Flint, M., El-Alayli, A., Ridnour, H., \& Peterson, M. (2005). Gender differences in spiritual well-being: are females more spiritually-well than males? American Journal of Health Studies, 20.

Harvey, M. B. (2004). Development and psychometric validation of the State-Trait Spirituality Inventory (Doctoral dissertation, University of North Texas).

Hill, P. C., \& Hood, R. W. (Eds.). (1999). Measures of religiosity (pp. 119-58). Birmingham, AL: Religious Education Press.

Hodge, D. R. (2003). The intrinsic spirituality scale: A new six-item instrument for assessing the salience of spirituality as a motivational construct. Journal of Social Service Research, 30(1), 41-61. https://doi.org/10.1037/t01595-000

Hooker, S. A., Masters, K. S., \& Carey, K. B. (2014). Multidimensional assessment of religiousness/spirituality and health behaviors in college students. The International Journal for the Psychology of Religion, 24(3), 228-240.

Jafari, E., Dehshiri, G. R., Eskandari, H., Najafi, M., Heshmati, R., \& Hoseinifar, J. (2010). Spiritual well-being and mental health in university students. Procedia-Social and Behavioral Sciences, 5, 1477-1481.

Jagers, R. J., \& Smith, P. (1996). Further examination of the spirituality scale. Journal of Black Psychology, 22(4), 429-442. https://doi.org/10.1177/00957984960224002

Johnson, M. J., \& Reynolds, A. L. (2018). Factors influencing academic success among african american college women: The impact of african american acculturation and religiosity. Journal of Black Psychology, 44(5), 403-421.

Josselson, R. (1987). Finding herself: Pathways to identity development in women. Jossey-Bass.

Kass, J. D., Friedman, R., Leserman, J., Zuttermeister, P. C., \& Benson, H. (1991). Health outcomes and a new index of spiritual experience. Journal for the Scientific Study of Religion, 203-211.

Kellums, K. J. (1995). Gender analysis of the spiritual well-being scale.

Krosnick, J. A. (2018). Questionnaire design. In The Palgrave Handbook of Survey Research (pp. 439-455). Palgrave Macmillan, Cham. https://doi.org/10.1007/978-3-319-54395-6_53

Kuh, G. D., \& Gonyea, R. M. (2006). Spirituality, Liberal Learning, and College Student Engagement. Liberal Education, 92(1), 40-47.

MacMillan, T., \& Luna, N. (2016). A confirmatory factor analysis of the Spiritual Transcendence Index: assessing spirituality in a sample of Latino college students. Mental Health, Religion \& Culture, 19(5), 464-475.

Mehri, A., Solhi, M., Garmaroudi, G., Nadrian, H., \& Sighaldeh, S. S. (2016). Health promoting lifestyle and its determinants among university students in Sabzevar, Iran. International Journal of Preventive Medicine, 7.

Miller, J. B. (2012). Toward a new psychology of women. Beacon Press.

Moloney, S., \& Gair, S. (2015). Empathy and spiritual care in midwifery practice: Contributing to women's enhanced birth experiences. Women and Birth, 28(4), 323-328. https://doi.org/10.1016/j.wombi.2015.04.009

Musgrave, C. F., Allen, C. E., \& Allen, G. J. (2002). Spirituality and health for women of color. American Journal of Public Health, 92(4), 557-560. https://doi.org/10.2105/AJPH.92.4.557

Nadeem Luqman, D., Puri, A., \& Tanwar, K. C. (2015). Gender differences in spiritual personality. Int. J. of Multidisciplinary and Current research, 3, 719-722.

Nagel, E., \& Sgoutas-Emch, S. (2007). The relationship between spirituality, health beliefs, and health behaviors in college students. Journal of Religion and Health, 46(1), 141-154. 
https://doi.org/10.1007/s10943-006-9088-8

Ochs, C. (1997). Women and spirituality (No. 67). Rowman \& Littlefield.

Ozorak, E. W. (1996). The power, but not the glory: How women empower themselves through religion. Journal for the Scientific Study of Religion, 35, 17-29. https://doi.org/10.2307/1386392

Paloutzian, R. F., \& Ellison, C. W. (1982). Loneliness, spiritual well-being and the quality of life. Loneliness: A sourcebook of current theory, research and therapy, 224-237.

Puchalski, C., \& Romer, A. L. (2000). Taking a spiritual history allows clinicians to understand patients more fully. Journal of palliative medicine, 3(1), 129-137. https://doi.org/10.1089/jpm.2000.3.129

Reed, P. G. (1987). Spirituality and well-being in terminally ill hospitalized adults. Research in nursing \& health, 10(5), 335-344. https://doi.org/10.1002/nur.4770100507

Reid, M., Roumpi, D., \& O'Leary-Kelly, A. M. (2015). Spirited women: The role of spirituality in the work lives of female entrepreneurs in Ghana. Africa Journal of Management, 1(3), 264-283. https://doi.org/10.1080/23322373.2015.1062710

Pargament, K. I. (2001). The psychology of religion and coping: Theory, research, practice. Guilford Press.

Parks, S. D. (2011). Big questions, worthy dreams: Mentoring emerging adults in their search for meaning, purpose, and faith. John Wiley \& Sons.

Portney, L. G., \& Watkins, M. P. (2009). Foundations of clinical research: applications to research. Survey of Ophthalmology, 00362-4.

Ryan, M. K., David, B., \& Reynolds, K. J. (2004). Who cares? The effect of gender and context on the self and moral reasoning. Psychology of women quarterly, 28(3), 246-255. https://doi.org/10.1111/j.1471-6402.2004.00142.x

Sandage, S. J., Jankowski, P. J., Crabtree, S. A., \& Schweer-Collins, M. L. (2017). Calvinism, gender ideology, and relational spirituality: An empirical investigation of worldview differences. Journal of Psychology and Theology, 45(1), 17-32. https://doi.org/10.1177/009164711704500102

Shin, J. Y., \& Steger, M. F. (2016). Supportive college environment for meaning searching and meaning in life among American college students. Journal of College Student Development, 57(1), 18-31. https://doi.org/10.1037/t64681-000

Shukla, D., Sharma, S. D., Sharma, S. K., \& Pragyendu. (2016). Gender, education and spiritual health: An exploratory analysis. Indian Journal of Health \& Wellbeing, 7(1), 91-96.

Stevens, J. P. (2012). Applied multivariate statistics for the social sciences. Routledge.

Ward, S. J., \& King, L. A. (2018). Gender differences in emotion explain women's lower immoral Intentions and harsher moral condemnation. Personality and Social Psychology Bulletin, 44(5), 653-669. https://doi.org/10.1177/0146167217744525

Weathers, E., McCarthy, G., \& Coffey, A. (2016). Concept analysis of spirituality: An evolutionary approach. In Nursing Forum. 51(2) 79-96. https://doi.org/10.1111/nuf.12128

Yong, A. G., \& Pearce, S. (2013). A beginner's guide to factor analysis: Focusing on exploratory factor analysis. Tutorials in quantitative methods for psychology, 9(2), 79-94. https://doi.org/10.20982/tqmp.09.2.p079

\section{Copyrights}

Copyright for this article is retained by the author(s), with first publication rights granted to the journal.

This is an open-access article distributed under the terms and conditions of the Creative Commons Attribution license (http://creativecommons.org/licenses/by/4.0/). 